\title{
BMJ Global Health Essential Emergency and Critical Care: a consensus among global clinical experts
}

To cite: Schell CO, Khalid $\mathrm{K}$, Wharton-Smith A, et al. Essential Emergency and Critical Care: a consensus among global clinical experts. BMJ Global Health 2021;6:e006585. doi:10.1136/ bmjgh-2021-006585

Handling editor Seye Abimbola

- Additional supplemental material is published online only. To view, please visit the journal online (http://dx.doi.org/10. 1136/bmjgh-2021-006585)

Received 14 June 2021 Accepted 19 August 2021
Check for updates

(c) Author(s) (or their employer(s)) 2021. Re-use permitted under CC BY. Published by BMJ.

For numbered affiliations see end of article.

Correspondence to Dr Carl Otto Schell; Carl.Schell@ki.se

\section{ABSTRACT}

Background Globally, critical illness results in millions of deaths every year. Although many of these deaths are potentially preventable, the basic, life-saving care of critically ill patients are often overlooked in health systems. Essential Emergency and Critical Care (EECC) has been devised as the care that should be provided to all critically ill patients in all hospitals in the world. EECC includes the effective care of low cost and low complexity for the identification and treatment of critically ill patients across all medical specialties. This study aimed to specify the content of EECC and additionally, given the surge of critical illness in the ongoing pandemic, the essential diagnosisspecific care for critically ill patients with COVID-19. Methods In a Delphi process, consensus (> $90 \%$ agreement) was sought from a diverse panel of global clinical experts. The panel iteratively rated proposed treatments and actions based on previous guidelines and the WHO/ICRC's Basic Emergency Care. The output from the Delphi was adapted iteratively with specialist reviewers into a coherent and feasible package of clinical processes plus a list of hospital readiness requirements.

Results The 269 experts in the Delphi panel had clinical experience in different acute medical specialties from 59 countries and from all resource settings. The agreed EECC package contains 40 clinical processes and 67 requirements, plus additions specific for COVID-19. Conclusion The study has specified the content of care that should be provided to all critically ill patients. Implementing EECC could be an effective strategy for policy makers to reduce preventable deaths worldwide.

\section{INTRODUCTION}

Critical illness, when defined as a state of ill health with vital organ dysfunction and a high risk of imminent death, is common in hospitals throughout the world. ${ }^{1-6}$ It is the most severe form of acute illness due to any underlying condition and results in millions of deaths globally every year. ${ }^{15}$ The COVID-19 pandemic has led to increased morbidity and mortality with a surge in critical illness worldwide. ${ }^{7-9}$

\section{WHAT IS ALREADY KNOWN?}

$\Rightarrow$ Critical illness is common throughout the world and COVID-19 has caused a global surge of critically ill patients.

$\Rightarrow$ There are large gaps in the quality of care for critically ill patients, especially in low-staffed and lowresourced settings, and mortality rates are high.

$\Rightarrow$ Essential Emergency and Critical Care (EECC) is the effective lifesaving care of low-cost and lowcomplexity that all critically ill patients should receive in all wards in all hospitals in the world.

\section{WHAT ARE THE NEW FINDINGS?}

$\Rightarrow$ The clinical processes that comprise EECC and the essential care of critically ill patients with COVID-19 have been specified in a large consensus among clinical experts worldwide.

$\Rightarrow$ The resource requirements for hospitals to be ready to provide this care has been described.

\section{WHAT DO THE NEW FINDINGS IMPLY?}

$\Rightarrow$ The findings can be used across medical specialties in hospitals worldwide to prioritise and implement essential care for reducing preventable deaths.

$\Rightarrow$ Inclusion of the EEEC processes could increase the impact of pandemic preparedness and response programmes and policies for health systems strengthening.

Many of the deaths due to critical illness are potentially preventable. ${ }^{10-12}$ In critical illness, the patient's airway, breathing or circulation may become compromised, and early identification of the problem and timely care can be lifesaving. Unfortunately, this care is frequently a neglected part of healthcare. The basic, life-saving clinical processes may be overlooked in specialised care $^{12}$ and in settings of both high ${ }^{13-15}$ and low resources. ${ }^{16-18}$ In hospitals all over the world, guidelines, equipment and routines focusing on the care of critically ill patients, are often missing for adult ${ }^{19}$ and paediatric patients, ${ }^{11}$ in emergency units, ${ }^{20}$ in wards ${ }^{21}$ 


\section{PHASE 1: DELPHI CONSENSUS ABOUT TREATMENTS AND ACTIONS}

- Drafting individual T\&A based on tools from WHO and related specialties

- Deciding the T\&As to include in the Delphi together with specialist reviewers

- Inviting clinical experts with diverse backgrounds to participate in the Delphi panel

- Seeking consensus (>90\% agreement) for the T\&A in three Delphi rounds

\section{PHASE 2: EECC PACKAGE OF CLINICAL PROCESSES}

- Adjusting the wording of the T\&A to ensure language consistency

- Minor modifications to the T\&A to reassemble into clinical processes

- Iterative adjustments by specialist reviewers to ensure relevance for all acute medical specialties and to form a final coherent, feasible package of clinical processes in EECC

\section{PHASE 3: HOSPITAL READINESS REQUIREMENTS}

- Reviewing WHO tools, guidelines for related specialties and facility preparedness lists to form a provisional list of resources required to conduct the clinical processes

- Iterative input from the specialist reviewers to approve suggested items, add relevant items from their clinical specialties, and suggest modifications, resulting in a final list of hospital readiness requirements in EECC

Figure 1 The study process. EECC, Essential Emergency and Critical Care; T\&A, Treatment and actions.

and in intensive care units. ${ }^{22}$ Improving the way healthcare manages critical illness could save many lives. ${ }^{112324}$

To improve outcomes for critically ill patients by means that are feasible to deliver in all hospital wards and settings, the Essential Emergency and Critical Care (EECC) concept was devised. ${ }^{25}$ EECC is defined as the care that should be provided to all critically ill patients of all ages in all hospitals in the world. It is distinguished by three principles. First, priority to those with the most urgent clinical need, including both early identification and timely care. Second, provision of the life-saving treatments that support and stabilise failing vital organ functions. And third, a focus on effective care of low cost and low complexity.

The clinical processes that comprise the essential care of critically ill patients, and the resources required for those processes have not previously been specified. As critically ill patients can be suffering from any underlying condition, EECC is conceptualised to be integrated into all acute clinical specialties. We therefore sought consensus among a diverse group of global clinical experts with the aim of specifying the content of EECC. An additional aim, given the ongoing pandemic, was consensus around the essential diagnosis-specific care for critically ill patients with COVID-19.

\section{METHODS}

The study used three phases (figure 1). First, a consensus was sought about the treatments and actions (T\&A) in
EECC using a modified Delphi technique. ${ }^{26}$ Second, the output from the Delphi was adjusted into a coherent, user-friendly and feasible package of clinical processes. And third, a list of requirements for hospitals to be ready to provide the care was developed.

\section{Phase I}

An online, three-round modified Delphi process was conducted in November and December 2020. The Delphi method uses anonymous responses from an expert panel to iteratively posed questions and controlled feedback to reach consensus on the topic of interest. ${ }^{26} \mathrm{~A}$ Delphi process was chosen for this study as EECC is new, its content has not been previously specified and a large group of diverse experts was required.

To be part of the panel, experts needed to have clinical experience of caring for critically ill patients. To ensure the involvement of a diverse range of experts, it was decided that at least $50 \%$ of the invitations to participate in the panel should be sent to experts with substantial experience working in low-income and middle-income countries, and there should be a balance between clinical experience (work in general wards, emergency units, intensive care units); specialty (paediatrics, obstetrics, medicine, surgery, intensive care, anaesthesia and emergency care); profession (doctors, nurses, other health professionals); location and gender. A list of potential participants was made from a mapping of stakeholders, the literature across all acute medical specialties, the 
researchers' networks and additional purposive and snowball sampling for under-represented groups. Additionally, a link to a screening survey was sent to global professional networks, specialist societies and on social media to identify further potential participants. A total of 895 experts were invited to participate, and those who accepted provided written informed consent.

EECC consists of clinical processes of care. To enable rating by the Delphi panel, clinical processes were disassembled into individual T\&A. The T\&A concern the identification of critical illness; care of critical illness, and the diagnosis-specific care of critically ill patients with COVID-19. To be included, all T\&A were required to meet two a priori defined criteria: effectiveness ${ }^{i}$ and feasibility. ${ }^{\mathrm{i}}$ Additionally, universality ${ }^{\mathrm{i}}$ was required for the identification and care of critical illness and relevance $e^{i}$ was required for the diagnosis-specific care of critically ill patients with COVID-19. A draft list of potential T\&A was developed based on clinical guidelines and tools from related specialties ${ }^{27-38}$ and aligned with the WHO/ International Committee of the Red Cross's (ICRC) Basic Emergency Care ${ }^{39}$ The draft list was revised by specialist reviewers-a group of senior clinicians, researchers and policy makers, with expertise in paediatrics, medicine, emergency medicine, anaesthesia and intensive care, critical care nursing, obstetrics and gynaecology, and surgery.

Three Delphi rounds were deemed sufficient to address the aim while avoiding attrition and poor response rates. A 4-point Likert scale (strongly disagree, disagree, agree, strongly agree) with a 'do-not know' option was used for the panel to rate their opinion about the inclusion of each T\&A in EECC. ${ }^{40-42}$ Consensus was achieved when more than $90 \%$ of respondents selected 'agree' or 'strongly agree', excluding 'don't know' responses. The experts were able to provide free-text comments, which were analysed to identify appropriate, relevant changes to the wording of T\&A for clarity of understanding, and to identify newly proposed T\&A. After the first round, newly proposed T\&A that fulfilled the EECC criteria for potential inclusion were revised after input from the specialist reviewers and included for assessment by the panel. T\&A that did not reach consensus in the previous round were presented for reassessment in rounds two and three, together with a visual representation of the spread of previous responses.

As the Delphi panel was diverse, it was considered that there may be different opinions about the inclusion of

\footnotetext{
${ }^{\mathrm{i}}$ Effectiveness: established or proven to be safe and to reduce mortality (compression to stop bleeding is effective; treating with leech therapy is not). Feasibility: low-cost and low complexity. Possible to provide in a low-staffed, low-resourced setting without the immediate presence of a doctor (placing a comatose patient in the recovery position (lateral position) is feasible; continuous haemodialysis is not). Universality: supports vital organ function rather than being the definitive care of a diagnosis (intravenous fluids for shock are universal; thrombolytic therapy is not). Relevance: established or proven to be a treatment for COVID-19.
}

Table 1 The characteristics of the expert panel in the Delphi (first round)

\begin{tabular}{|c|c|c|}
\hline & $\begin{array}{l}\text { Number of } \\
\text { experts } \\
(\mathrm{N}=269)\end{array}$ & $\begin{array}{l}\text { Proportion of } \\
\text { experts } \\
(\%)^{\star}\end{array}$ \\
\hline \multicolumn{3}{|l|}{ Resource setting* } \\
\hline High-income country & 139 & 52 \\
\hline Middle-income country & 115 & 43 \\
\hline Low-income country & 177 & 66 \\
\hline Do not know & 2 & 1 \\
\hline \multicolumn{3}{|l|}{ Clinical setting ${ }^{\star}$} \\
\hline General ward & 153 & 57 \\
\hline Emergency unit & 179 & 67 \\
\hline High dependency unit & 153 & 57 \\
\hline Intensive care unit & 232 & 86 \\
\hline Operating theatre & 102 & 38 \\
\hline Other & 15 & 6 \\
\hline \multicolumn{3}{|l|}{ Specialty* } \\
\hline Emergency care & 93 & 35 \\
\hline Intensive care & 190 & 71 \\
\hline Anaesthesia & 59 & 22 \\
\hline Medicine & 39 & 15 \\
\hline Surgery & 20 & 7 \\
\hline Paediatrics & 47 & 17 \\
\hline Obstetrics/gynaecology & 13 & 5 \\
\hline Other & 25 & 9 \\
\hline \multicolumn{3}{|l|}{ Profession* } \\
\hline Doctor & 212 & 79 \\
\hline Nurse & 40 & 15 \\
\hline Midwife & 6 & 2 \\
\hline Clinical officer & 9 & 3 \\
\hline Other & 17 & 6 \\
\hline \multicolumn{3}{|l|}{ Gender* } \\
\hline Female & 102 & 38 \\
\hline Male & 165 & 62 \\
\hline
\end{tabular}

*As the experts were asked to select all that apply, the sum of the percentages may exceed 100 .

T\&As between experts with particular a priori defined characteristics. These subgroups of experts were those with work experience in a low-income country or not; those who are doctors or not; those with clinical experience in emergency care and those without; and those with clinical experience in intensive care and those without. The levels of agreement in each subgroup were assessed and presented for all the T\&As that reached consensus.

\section{Phase II}

After the Delphi, slight adjustments were made to the wording of the T\&A that had reached consensus to 
ensure language consistency. The T\&A were reassembled back into clinical processes to increase overall coherence and feasibility of the EECC package, with the goal of user-friendliness for health system implementation and quality improvement work. The adjustments were done in an iterative process with the same specialist reviewers as in Phase I to ensure relevance for all acute medical specialties. The final package of clinical processes was organised into those relevant for identification, for care and general processes.

\section{Phase III}

A provisional list of hospital readiness requirements for the provision of the clinical processes were developed using existing WHO tools, guidelines for related specialties, facility preparedness lists ${ }^{29} 32343537-394344$ and the experience and knowledge of the study team. The specialist reviewers provided iterative input into the provisional list, approving suggested items, adding relevant items from their clinical specialties and suggesting modifications. Based on previous work and following consultation with health economists and procurement experts, the final list of requirements was agreed and arranged into eight categories: equipment, consumables, drugs, human resources, training, routines, guidelines and infrastructure.

\section{Patient and public involvement}

Patients and the public were not involved in the design and conduct of the research.

\section{RESULTS}

\section{Phase I}

Of the 895 invited experts, 269 participated in the first round of the Delphi when the majority of the decisions were made $(30 \%$ response rate). In round 2 , 228 experts participated ( $85 \%$ of those in round 1$)$ and round 3 included 194 experts $(85 \%$ of those in round 2 ). The panel comprised experts from diverse resource settings, clinical settings, specialties and professions (table 1). The panel included experts from 59 countries (figure 2) and $38 \%$ were female.

Of the 57 T\&A for EECC in round 1, consensus was reached for 49. In round 2, 29 newly proposed T\&A were added to the eight remaining from round 1 , of which two had been reworded for clarity. Out of these 37 , consensus was reached for 17 . The remaining 20 , of which another two had been reworded for clarity, were included in round 3. Consensus was reached for nine of the final 20 T\&A. In total, consensus was reached for 75 out of 86 proposed T\&A, including 54 of the original 57 (online supplemental table 1 ).

Of the seven T\&A for the essential diagnosis-specific care of critically ill COVID-19 in round 1 , all reached consensus for inclusion. In round 2, two newly proposed T\&A were added. Neither of these reached consensus in round 2 or round 3 .

Analyses of participant subgroups did not reveal substantial divergence from the overall results. For the T\&A that reached $90 \%$ agreement in the panel, agreement was not below $80 \%$ in any subgroup (online supplemental tables 2-4).

\section{Phase II and III}

After the Delphi, the T\&A that had reached consensus were reassembled into a final user-friendly and feasible package of EECG containing 40 clinical processes-30 identification and care processes and 10 general processes (table 2). All T\&A for the care of critical illness were included, with some rewording and reordering.

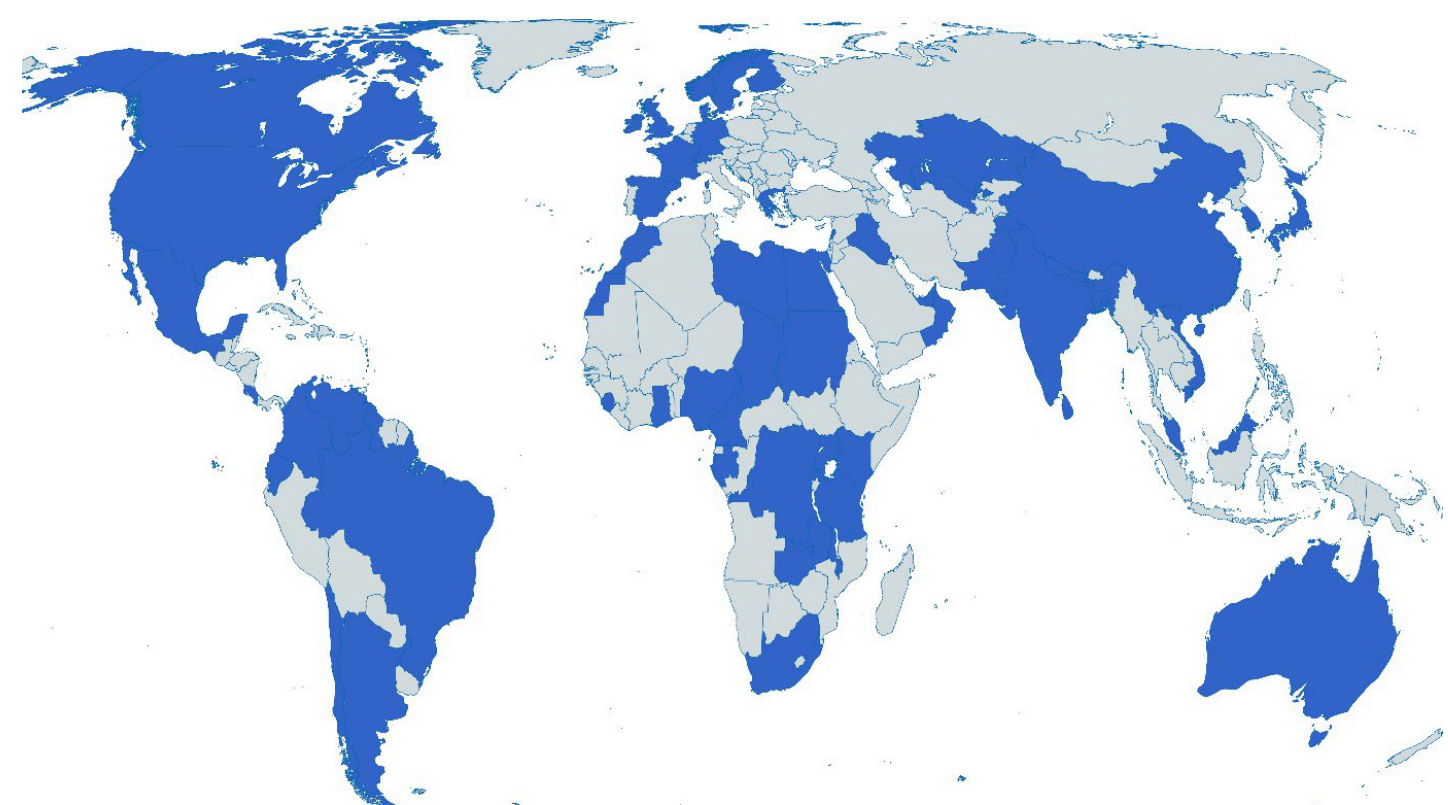

Figure 2 The expert panel locations. Created with mapchart.net. Disclaimer: the depictions of boundaries are not warranted to be error free. 

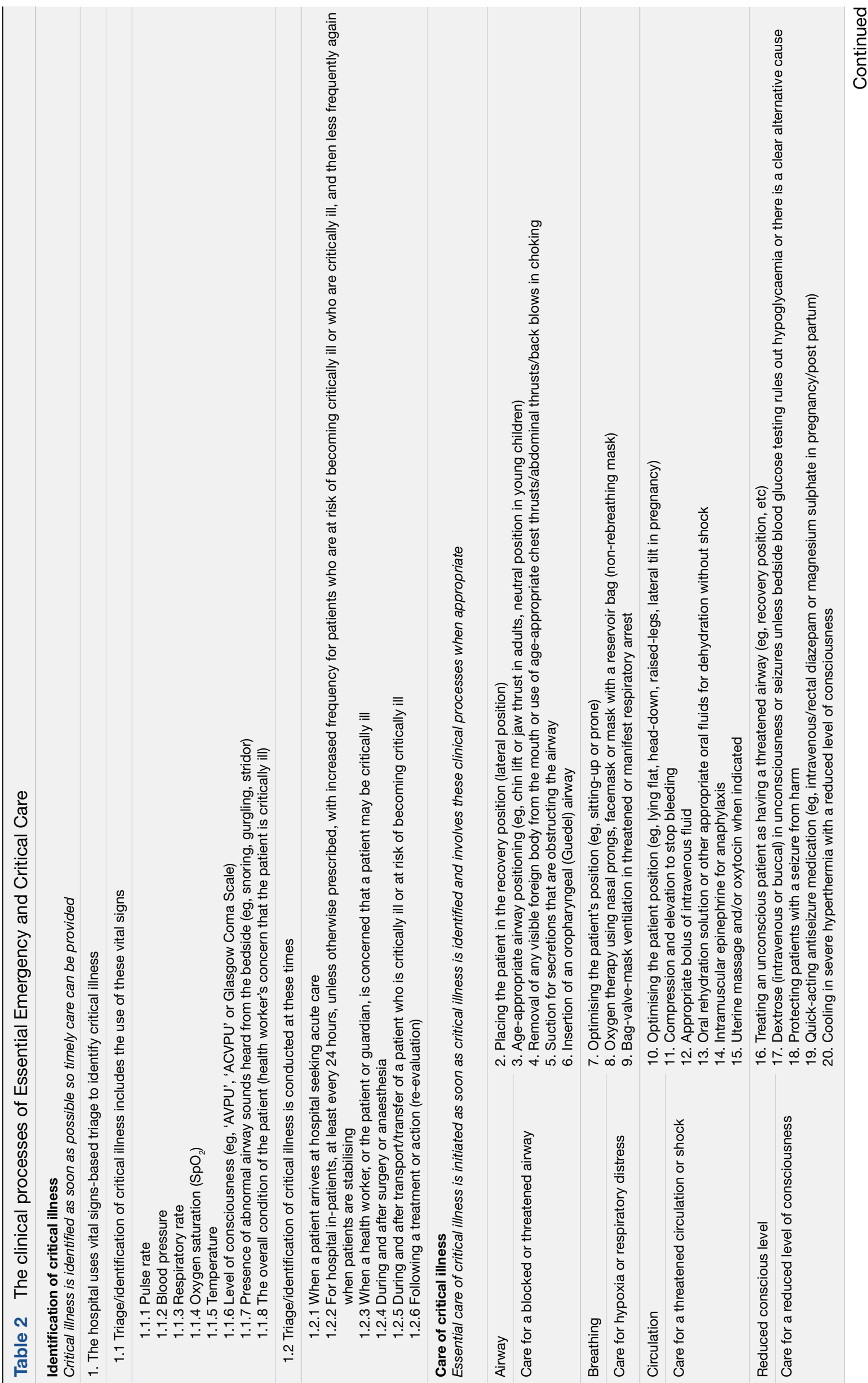


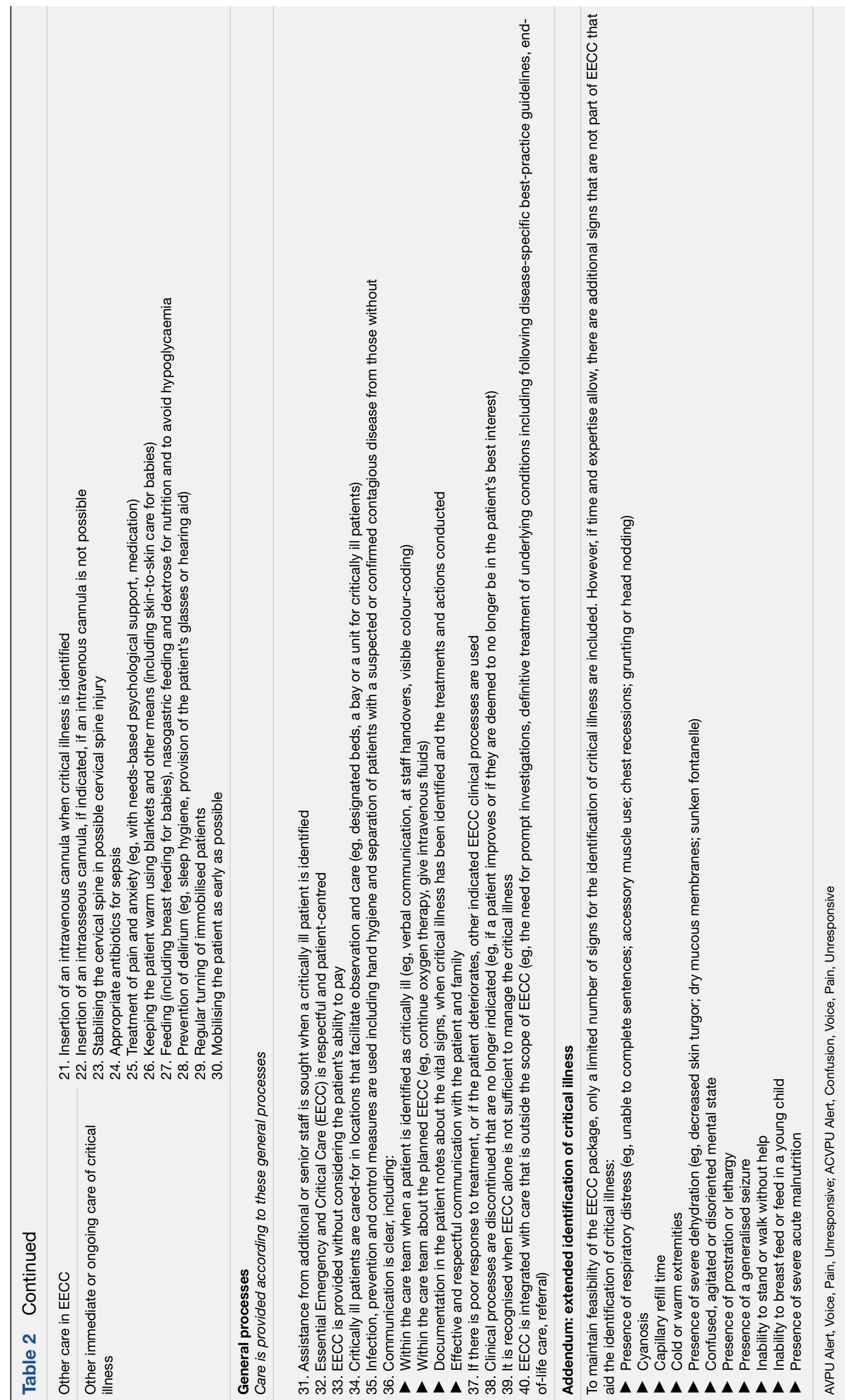


Eleven T\&A for the identification of critical illness were not included, so that the package could be feasible for triage in all hospitals, and were added as an addendum (outside the remit of EECC), in order to underscore their importance in settings where staff have sufficient time and expertise.

The list of hospital readiness requirements for EECC contained 67 items, (14 for identification and 53 for essential care) (table 3).

The essential diagnosis-specific care of critically ill patients with COVID-19 consisted of an additional seven clinical processes and nine hospital readiness requirements (table 4).

\section{DISCUSSION}

We have specified the content of EECC based on consensus among global clinical experts. While the EECC approach is new, the included clinical processes are commonly used in the care of sick patients and can be seen in WHO publications and specialist society standards and guidelines. ${ }^{29}{ }^{32-35} 383945$ The contribution of this study is the specification of a baseline bundle of care interventions that should be provided when needed to all critically ill patients in all hospitals in the world. This marks a break from previous guidelines that tend to be specialty-specific, condition-specific or location-specific, or that specify care that may be too complex and costly to provide in all hospital settings.

\section{The EECC approach}

EECC is an approach that supports priority-setting in health systems. In this regard, it has parallels to the approaches used in the WHO's Essential Medicines List, ${ }^{37}$ Interagency Integrated Triage Tool ${ }^{29}$ Emergency Triage and Treatment for Children ${ }^{32}$ and Universal Health Coverage ${ }^{36}$ EECC emphasises the identification and care of the critically ill, and the provision of the life-saving supportive care that is of low cost and of low complexity. ${ }^{25}$ EECC can be seen as a unifying concept for such aspects of patient management found in WHO and specialist guidelines, triage, early warning systems and rapid response teams. ${ }^{28} 29394647$ To maintain focus on life-saving supportive care and to be useful across all specialties, EECC does not include the definitive care of the underlying diagnoses. Instead, EECC is intended to complement specialty-based care and existing guidelines and does not aim to include all the care a patient needs-as well as EECC, patients should receive diagnostics, definitive and symptomatic care of their condition, additional nursing care, and if available, higher levels of emergency and critical care. EECC seeks to bridge the quality gap that is commonly found between the current care of critical illness and best-practice guidelines. ${ }^{12} 4849$ To ensure feasibility in settings with restricted human resources, EECC is designed to enable task-sharing between health professionals. ${ }^{50}$ It should be noted that not all the EECC clinical processes will be needed in the care of every critically ill patient-they should be seen as essential 'tools in the tool-box' for health workers to use when required. To operationalise the EECC approach, it is intended that the content specified here is used to develop tools for quality monitoring, teaching and integration into other guidelines and recommendations.

\section{EECC complements the current healthcare organisation}

The basic clinical processes specified in EECC have been overlooked in healthcare. ${ }^{11} 13-1518205152$ In UK hospitals, half of the patients received substandard basic vital organ support prior to intensive care and $31 \%$ of preventable deaths were associated with absent clinical monitoring. ${ }^{13}{ }^{14}$ In Malawi, $89 \%$ of adult hypoxic patients and $75 \%$ of children dying from pneumonia in hospital did not receive oxygen. ${ }^{17} 18$ The usual organisational set-up of health services may be one underlying reason for this. Specialist units with a primary function of delivering the definitive management for one disease group may underestimate the effort needed to maintain core processes and competences in the supportive management of critically ill patients. Innovative and specialised treatments and technologies may become preferred to those that are basic and long-standing. ${ }^{53}$ By targeting a feasible, lowest baseline quality for critically ill patients throughout hospital settings, EECC provides a complimentary approach to the current organisation that safeguards the provision of basic life-saving actions, enhancing the impact of hospital care for all acute conditions.

\section{EECC in the COVID-19 pandemic}

EECC has added importance in a situation causing a substantial amount of severe disease and the Delphi panel agreed that EECC should be part of the care of critically ill patients with COVID-19. In addition, the agreed essential diagnostic-specific care for COVID-19 can assist in decisions about the priorities of care when the pandemic threatens to overwhelm available resources. All of the COVID-19 specific processes are well established and are included in the WHO COVID-19 clinical management guidance. ${ }^{30}$ The WHO guidance, and others, ${ }^{54}$ additionally include recommendations for advanced critical care (such as mechanical ventilation, vasopressors and extracorporeal oxygenation), which may be difficult to rapidly scale-up in settings of low resources. Advanced critical care can be necessary to save the lives of some patients, but has a high cost per recovery and risks diverting scarce resources to a few individuals. ${ }^{55-60}$ Fortunately, the focus has shifted in the global pandemic response from advanced critical care towards securing basic oxygen delivery systems ${ }^{61} 62$ underscored by statements from the WHO and other partners. ${ }^{63} 64$ The impact of this shift, in and beyond 
Table 3 The hospital readiness requirements for Essential Emergency and Critical Care

\section{Identification of critical illness}

The following items are required for a hospital to be ready for the identification of critically ill patients

\section{Category}

1.1. Equipment

\section{Item}

1.1.1 Clock with secondhand

1.1.2 Pulse oximeter and probe

1.1.3 Blood pressure measuring equipment (eg, sphygmomanometer with a stethoscope)

1.1.4 Blood pressure cuffs of different paediatric and adult sizes

1.1.5 Light source (lamp or flashlight)

1.1.6 Thermometer

1.2 Consumables $\quad$ 1.2.1 Soap or hand disinfectant

1.2.2 Examination gloves

\subsection{Drugs}

1.4 Human

None

resources

$\begin{array}{ll}\text { 1.5 Training } & \text { 1.5.1 The health workers are trained in the identification of critical illness } \\ \text { 1.6 Routines } & \text { 1.6.1 Routines for the identification of critical illness } \\ \begin{array}{l}\text { 1.7 Guidelines } \\ \text { 1.8 Infrastructure }\end{array} & \begin{array}{l}\text { 1.8.1 } \text { Designated triage area (area for the identification of critical illness) in the Out-Patient Department or } \\ \text { Emergency Unit (area of the hospital where patients arrive) } \\ \text { 1.8.2 Running water }\end{array}\end{array}$

\section{Care of critical illness}

The following items are required for a hospital to be ready to provide the care of critically ill patients

\subsection{Equipment}

2.2 Consumables
2.1.1 Suction machine (electric or manual)

2.1.3 Oxygen supply 24 hours/day (cylinder, concentrator (with electricity supply) or piped oxygen)

2.1.4 Flow meter (if using cylinder or piped oxygen)

2.1.5 Leak-free connectors from oxygen source to tubing

2.1.6 Bag valve mask (resuscitator) - neonatal, paediatric and adult sizes

2.1.7 Sharps disposal container

2.1.8 External heat source

2.2.1 Suction catheters of paediatric and adult sizes

2.2.2 Guedel airways of paediatric and adult sizes

2.2.3 Pillows

2.2.4 Oxygen tubing

2.2.5 Oxygen nasal prongs

2.2.6 Oxygen face masks of paediatric and adult sizes

2.2.7 Oxygen face masks with reservoir bags of paediatric and adult sizes

2.2.8 Masks for bag valve mask (resuscitator) - neonatal, paediatric and adult sizes

2.2.9 Compression bandages

2.2.10 Plasters or tape

2.2.11 Gauze

2.2.12 Intravenous cannulas of paediatric and adult sizes

2.2.13 Intravenous giving sets

2.2.14 Skin disinfectant for cannulation

2.2.15 Syringes

2.2.16 Nutrition

2.2.17 Nasogastric tubes

2.2.18 Lubricant for nasogastric tube insertion

2.2.19 Intramuscular needles

2.2.20 Intraosseous cannulas of different sizes

2.2.21 Blankets

2.2.22 Facemasks for infection prevention and control

2.2.23 Aprons or gowns

2.2.24 Charts/notes for documentation

2.2.25 Pens 
Table 3 Continued

\begin{tabular}{|c|c|}
\hline 2.3 Drugs & $\begin{array}{l}\text { 2.3.1 Oral rehydration solution } \\
\text { 2.3.2 Intravenous crystalloid fluids (eg, normal saline or Ringer's Lactate) } \\
\text { 2.3.3 Intravenous dextrose fluid (eg, } 5 \%, 10 \% \text { or } 50 \%) \\
\text { 2.3.4 Oxytocin } \\
\text { 2.3.5 Epinephrine } \\
\text { 2.3.6 Appropriate antibiotics } \\
\text { 2.3.7 Diazepam } \\
\text { 2.3.8 Magnesium sulphate } \\
\text { 2.3.9 Paracetamol } \\
\text { 2.3.10 Local anaesthetic (eg, } 2 \% \text { lignocaine) (eg, for intraosseous cannulation) }\end{array}$ \\
\hline $\begin{array}{l}2.4 \text { Human } \\
\text { resources }\end{array}$ & $\begin{array}{l}\text { 2.4.1 Health workers with the ability to care for critically ill patients } 24 \text { hours/day } \\
\text { 2.4.2 Senior health worker who can be called to assist with the care of critically ill patients } 24 \text { hour/day }\end{array}$ \\
\hline 2.5 Training & 2.5.1 The health workers are trained in the care of critically ill patients \\
\hline 2.6 Routines & $\begin{array}{l}\text { 2.6.1 Routines for managing critically ill patients } \\
\text { 2.6.2 Routine for the provision of EECC without taking into account patients' ability to pay } \\
\text { 2.6.3 Routines for who and how to call to seek senior help } 24 \text { hours/day, } 7 \text { days/week } \\
\text { 2.6.4 Routines for integrating EECC with other care including the definitive care of the underlying } \\
\text { condition (eg, use of condition-specific guidelines) }\end{array}$ \\
\hline 2.7 Guidelines & 2.7.1 Guidelines for the essential care of critically ill patients \\
\hline 2.8 Infrastructure & $\begin{array}{l}\text { 2.8.1 Designated space for the care of critically ill patients (eg, a bay, ward, high dependency unit) } \\
\text { 2.8.2 Areas for separating and managing patients with a suspected or confirmed contagious disease from } \\
\text { those without }\end{array}$ \\
\hline
\end{tabular}

the pandemic, could be even greater if the necessary processes for the effective use of oxygen and other care specified in EECC were included in the scale-up.

\section{Strengths and limitations}

Our use of a consensus method with a large expert panel from diverse clinical and resource settings,

\section{Table 4 The essential diagnosis-specific care for critically ill patients with COVID-19}

\section{Clinical processes}

1. The Essential Emergency and Critical Care (EECC) clinical processes as specified for all critical illnesses

2. Personal protective equipment (PPE) that is appropriate for COVID-19 as part of infection, prevention and control

3. Monitoring oxygen saturation using pulse oximetry at least every 6 hours, unless otherwise prescribed

4. Intermittent prone positioning

5. Low molecular weight heparin or other anticoagulant

6. Corticosteroid

7. Antibiotics in patients with suspected bacterial superinfection

\section{Hospital readiness requirements}

Critically ill patients with COVID-19 require the same hospital readiness for EECC as other critically ill patients. For the provision of the essential diagnosis specific care of critically ill patients with COVID-19, the following additional items are required
Category
Item
3.1 Equipment
None
3.2 Consumables
3.2.1 Facemasks appropriate for COVID-19 (eg, N95)
3.2.2 Eye protection or face shields
3.3 Drugs
3.3.1 Low-molecular weight heparin (eg, enoxaparin or dalteparin) or other anticoagulant 3.3.2 Corticosteroid (eg, dexamethasone)
3.4 Human resource 3.4.1 Health workers with the ability to care for critically ill patients with COVID-19 24 hours/day
3.5 Training
3.5.1 The health workers are trained in essential care of critically ill patients with COVID-19
3.6 Routines
3.6.1 Routines for care of critically ill patients with COVID-19
3.7 Guidelines
3.7.1 Guidelines for essential care of critically ill patients with COVID-19
3.8 Infrastructure
3.8.1 Areas for separating and managing patients with suspected or confirmed COVID-19 from those without


specialties and geographical locations gives the specified content legitimacy. The high response rate for this type of study during an ongoing pandemic illustrates the interest that experts had in the project's aims. The high level of consensus $(>90 \%)$ for the included clinical processes promotes confidence in the final package. However, the Delphi method does have limitations. It is expert-opinion based and is limited by the make-up of the panel. Only English language speakers were included, experts were not included from all countries and the expedited timeline of the project due to the need for results that could impact the global response to the COVID-19 pandemic may have excluded experts who could have provided additional input. The initial content presented to the panel was aligned with WHO initiatives, ${ }^{39}$ and developed by a diverse specialist team, but the possibility remains that alternative methods would have led to a different output. The study did not address the underlying evidence-base for the included clinical processes, the impact, or the potential opportunity costs of increasing the coverage of EECC in hospitals-such system-wide effects warrant careful evaluation during EECC implementation. It should be noted that, while policy makers were involved throughout the process, the EECC content has not been ratified by the WHO or governmental ministries of health-the method has been primarily scientific. The findings should be seen as the first version of the EECC content, as recommended by global clinicians and researchers, one that could be incorporated into WHO and other global and national programmes and that should subsequently be improved and updated as new knowledge arises.

\section{Implications}

Implementation of EECC could be an effective strategy as part of the current calls to save lives through improved quality of care in health systems ${ }^{65}$-a 'lowhanging fruit'. Critically ill patients have high mortality rates in all hospital settings, especially where trained staff or resources are limited, and even small improvements in outcomes would have a large impact. EECC has a vital role in the ongoing COVID-19 pandemic, for the care of the surge of critically ill patients and for optimising the impact of the efforts to scale-up oxygen. Policy makers at global, national and regional levels aiming to reduce preventable deaths should focus on improved coverage of EECC and inclusion of EECC as part of universal health coverage. ${ }^{36}$

\section{CONCLUSION}

The content of EECC-and the essential care of critically ill patients with COVID-19-has been specified using an inclusive global consensus. The content consists of effective, low-cost and low-complexity lifesaving care that is still frequently overlooked. The time has come to ensure that all patients in the world receive this care.

\section{Author affiliations}

${ }^{1}$ Department of Global Public Health, Karolinska Institutet, Stockholm, Sweden ${ }^{2}$ Centre for Clinical Research Sörmland, Uppsala University, Eskilstuna, Sweden

${ }^{3}$ Department of Internal Medicine, Nyköping Hospital, Nyköping, Sweden

${ }^{4}$ Muhimbili University of Health and Allied Sciences, Dar es Salaam, United Republic of Tanzania

${ }^{5}$ Ifakara Health Institute, Dar es Salaam, United Republic of Tanzania

${ }^{6}$ Department of Global Health and Development, Faculty of Public Health and Policy, London School of Hygiene \& Tropical Medicine, London, UK

${ }^{7}$ KEMRI-Wellcome Trust Research Programme Nairobi, Nairobi, Kenya

${ }^{8}$ Department of Paediatrics \& Child Health, University of Nairobi, Nairobi, Kenya

${ }^{9}$ Emergency Medicine Department, Muhimbili University of Health and Allied

Sciences, Dar es Salaam, United Republic of Tanzania

${ }^{10}$ The George Institute for Global Health India, New Delhi, India

${ }^{11}$ WHO Collaborating Centre for Research in Surgical Care Delivery in LMICs, BARC Hospital, Mumbai, India

${ }^{12}$ Ministry of Health, Community Development, Gender, Elderly and Children,

Dodoma, United Republic of Tanzania

${ }^{13}$ Departments of Surgery and Critical Care Medicine, University of Toronto, Toronto, Ontario, Canada

${ }^{14}$ Malawi-Liverpool-Wellcome Trust Clinical Research Programme, Blantyre, Malawi

${ }^{15}$ Department of Disease Control, Faculty of Infectious and Tropical Disease, London School of Hygiene \& Tropical Medicine, London, UK

${ }^{16}$ Department of Anaesthesia and Intensive Care, Queen Elizabeth Central Hospital,

Blantyre, Malawi

${ }^{17}$ School of Public Health and Family Medicine, College of Medicine, Blantyre, Malawi

${ }^{18}$ Division of Emergency Medicine, University of Cape Town, Cape Town, South Africa

${ }^{19}$ Department of Health Sciences, The Red Cross University College, Huddinge, Sweden

${ }^{20}$ Department of Clinical Research, London School of Hygiene \& Tropical Medicine, London, UK

Twitter Carl 0tto Schell @CarlOttoSchell, Nobhojit Roy @nobsroy, Jamie Rylance @jamierylance and Maria Jirwe @mariajirwe

Acknowledgements We thank the World Federation of Intensive and Critical Care (WFICC) for supporting the study. We also thank all experts who participated in the Delphi panel, those who took part in piloting the questions, and Anders Wennerstrand for communications advice.

The EECC Collaborators (group authors) Adam Asghar, Adam D Laytin, Adrian J Holloway, Ahmed Rhassane El Adib, Alexia Michaelides, Alvaro Coronado Munoz, Amos Muzuka, Analía Fernández, Andrea B Pembe, Andreas Wellhagen, Andrew G Smith, Anita Gadgil, Anna Hvarfner, Anuja Abayadeera, Asya Agulnik, Aurélie Godard, Balasubramanian Venkatesh, Bargo Mahamat Yousif, Ben Morton, Bhakti Sarang, Bharath Kumar Tirupakuzhi Vijayaraghavan, Bobby King, Brian Rice, C Louise Thwaites, Chian Wern Tai, Christian Owoo, Cornelius Sendagire, Dan Brun Petersen, Daniel Tatay, David Lee Skinner, Denis Kinyua, Dhruva Ghosh, Diptesh Aryal, Donald Mlombwa, Duyen Thi Hanh Bui, Edwin R Lugazia, Elisabeth Riviello, Elizabeth M Molyneux, Ellena Heyns, Emmanuel Fru Nsutebu, Erika Montalvo, Ernesto Gerardo Moreno, Esther Banda Kanyangira, Fiona Muttalib, Francis Mupeta, Franco Diaz, Fred Bulamba, Furaha Nzanzu Blaise Pascal, Gavin Wooldridge, Gibonce Mwakisambwe, Guy A Richards, Hala Ammar, Halinder S Mangat, Hasanein H Ghali, Hiral A Shah, Hoi Ping Shum, Ibrahim Salim Abdullahi, Ignacio Martin-Loeches, Ingrid T von der Osten, Jacob Mcknight, James S Lee, Jane Kasozi Namagga, Jaran Eriksen, Jasmine ArmourMarshall, John Kellett, John Z Metcalfe, Jolene Moore, Jonas Blixt, Josephine Langton, Juan Gutierrez Mejia, Juan Ignacio Silesky-Jiménez, Kapil Dev Soni, Karl Martin Kohne, Kathryn Rowan, Kazuhiro Yokobatake, Kent Doi, Kristina E Rudd, Kwame Asante Akuamoah-Boateng, Lars Irestedt, Lia I Losonczy, Lina Zhang, Lisa Kurland, Lorna Guinness, Lovenish Bains, Margaret Nyaika, Markus Castegren, Matthew Loftus, Matti Reinikainen, Megan Cox, Mervyn Mer, Michael Jaung, Michael S Lipnick, Mike English, Miklos Lipcey, Monty Khajanchi, Mpoki Ulisubisya, Mulinda Nyirenda, Märit Amanda Halmin, Naman Shah, Natalie L Cobb, Nathan D Nielsen, Neill KJ Adhikari, Neville Vlok, Nicholas Risko, Niranjan Kissoon, Ntogwiachu Daniel Kobuh, Oscar Fernández Rostello, Patricia Duque, 
Paul D Sonenthal, Paul Patrick Mwasapi, Peter Baker, Petronella BjurlingSjöberg, Piedad Sarmiento, Pryanka Relan, Raymond Towey, Rebecca Silvers, Rehema Mlay, Rich Branson, Richard J Wang, Richard Kojan, Richard Peter Von Rahden, Richard Venn, Rob Mac Sweeney, Rodrigo Genaro Arduini, Rodwell Gundo, Ruyumbu Sixtus, Samson Kwazizira Mndolo, Samuel Akech, Shada A Rouhani, Siriel Nanzia Massawe, Stefan Swartling Peterson, Steven A Webb, Sunkaru Touray, Susana Guido, Teresa Kortz, Theodoros Aslanidis, Thomas G Weiser, Tom Bashford, Traci A Wolbrink, Usha Lalla, V Theodore Barnett, Vijay Christopher Kannan, Vincent loos, Waleed S Eldebsy, Wangari Waweru-Siika, Wezzie Kumwenda Mwafulirwa, William Obeng, Wim Van Damme, Yasein Omer, Zione Banda.

Contributors COS conceptualised and designed the study, acquired and analysed the data, and developed the first draft of the manuscript. TB and KK conceptualised and designed the study, and acquired and analysed the data. AW-S and MJ contributed to the design, acquisition and analysis of data. LAW provided input into study design and JO, HRS, NR, JCM, JR, CH and RK contributed to the design and analysis. All the authors interpreted the findings, critically revised the manuscript and approved the final version.

Funding This work was supported by the Wellcome Trust [221571/Z/20/Z], as part of the 'Innovation in low-and middle-income countries' Flagship. COS received grants from the Centre for Clinical Research Sörmland, Uppsala University [DLL941999].

Competing interests JCM declares personal fees from Gilead Pharmaceuticals, support for meetings from Sphingotec, participation in advisory boards for AKPA Pharma and AM Pharma, and the position of Associate Editor at Critical Care Medicine, all outside the submitted work. JR declares grants from Wellcome Trust, NIHR, and the position of Vice Chair of the Adult and Child Lung Health Section of the Union (unpaid). TB declares personal fees from UNICEF, the World Bank, USAID and the Wellcome Trust, all outside the submitted work. The other coauthors declare no conflicts of interest. Among the EECC Collaborators, AA declares the positions of Vice-Chair of the Rural Doctors of Southern Africa (RuDASA) and of the editorial board of South African Family Practice journal (both unpaid). AL declares personal fees from JHIPIEGO and the position of Vice-Chair of the International Federation of Emergency Medicine (IFEM) Critical Care subgroup (both unpaid). AREA declares the positions of Immediate Past President of the Moroccan Society of Anaesthesiology and Intensive Care (SMAR), of Vice-President of the Moroccan Society of Medical Simulation (Morocco Sim), of the African Regional Section World Federation of Societies of Anaesthesiologists (WFSA) Board and of the WFSA Safety and Quality of Practice Committee (all unpaid). BV declares speaking fees from Baxter and grants from NHMRC, MRFF and Baxter-all outside the submitted work. FB declares personal fees from Gradian Health, honoraria from Smile Train, and the position of member of the scientific committee of WFSA. JAM declares personal fees from the Swiss Institute of Tropical Medicine and Public Health outside the submitted work. MM declares the position as Chair of the European Society of Intensive Care Medicine (ESICM) Global Intensive Care Working Group. MSL declares grants from USAID Star outside the submitted work. PS declares payments from Drageer outside the submitted work. RPVH declares the position of the Scientific Advisory Board for Fresenius-Kabi South Africa 2019. The other EECC Collaborators declare no conflicts of interest.

\section{Patient consent for publication Not required.}

Ethics approval The study was approved by the London School of Hygiene and Tropical Medicine Research Ethics Committee (Ref: 22575). All participants in the Delphi panel provided written consent.

Provenance and peer review Not commissioned; externally peer reviewed.

Data availability statement All data relevant to the study are included in the article or uploaded as supplementary information. Access to anonymised data may be provided to researchers after provision of a study protocol and justification to the corresponding author.

Supplemental material This content has been supplied by the author(s). It has not been vetted by BMJ Publishing Group Limited (BMJ) and may not have been peer-reviewed. Any opinions or recommendations discussed are solely those of the author(s) and are not endorsed by BMJ. BMJ disclaims all liability and responsibility arising from any reliance placed on the content. Where the content includes any translated material, BMJ does not warrant the accuracy and reliability of the translations (including but not limited to local regulations, clinical guidelines, terminology, drug names and drug dosages), and is not responsible for any error and/or omissions arising from translation and adaptation or otherwise.
Open access This is an open access article distributed in accordance with the Creative Commons Attribution 4.0 Unported (CC BY 4.0) license, which permits others to copy, redistribute, remix, transform and build upon this work for any purpose, provided the original work is properly cited, a link to the licence is given, and indication of whether changes were made. See: https://creativecommons.org/ licenses/by/4.0/.

\section{ORCID iDs}

Carl Otto Schell http://orcid.org/0000-0002-7904-1336

Alexandra Wharton-Smith http://orcid.org/0000-0001-5335-2059

Hendry R Sawe http://orcid.org/0000-0002-0395-5385

Nobhojit Roy http://orcid.org/0000-0003-2022-7416

John C Marshall http://orcid.org/0000-0002-7902-6291

Claudia Hanson http://orcid.org/0000-0001-8066-7873

Lee A Wallis http://orcid.org/0000-0003-2711-3139

Maria Jirwe http://orcid.org/0000-0003-4570-4047

Tim Baker http://orcid.org/0000-0001-8727-7018

\section{REFERENCES}

1 Adhikari NKJ, Fowler RA, Bhagwanjee S, et al. Critical care and the global burden of critical illness in adults. Lancet 2010;376:1339-46.

2 Dart PJ, Kinnear J, Bould MD, et al. An evaluation of inpatient morbidity and critical care provision in Zambia. Anaesthesia 2017;72:172-80.

3 Bell MB, Konrad D, Granath F, et al. Prevalence and sensitivity of MET-criteria in a Scandinavian university hospital. Resuscitation 2006;70:66-73.

4 Kruisselbrink R, Kwizera A, Crowther M, et al. Modified early warning score (MEWS) identifies critical illness among ward patients in a resource restricted setting in Kampala, Uganda: a prospective observational study. PLoS One 2016;11:e0151408.

5 Rudd KE, Johnson SC, Agesa KM, et al. Global, regional, and national sepsis incidence and mortality, 1990-2017: analysis for the global burden of disease study. The Lancet 2020;395:200-11.

6 Razzak J, Usmani MF, Bhutta ZA. Global, regional and national burden of emergency medical diseases using specific emergency disease indicators: analysis of the 2015 global burden of disease study. BMJ Glob Health 2019;4:e000733.

7 Karlinsky A, Kobak D. The world mortality dataset: tracking excess mortality across countries during the COVID-19 pandemic. medRxiv 2021 [Preprint].10.1101/2021.01.27.21250604. [Epub ahead of print: 04 Jun 2021]

8 Endris BS, Saje SM, Metaferia ZT. Excess mortality in the face of COVID-19: evidence from Addis Ababa mortality surveillance program. Lancet 2021 [Preprint]

9 Tyrrell CSB, Mytton OT, Gentry SV, et al. Managing intensive care admissions when there are not enough beds during the COVID-19 pandemic: a systematic review. Thorax 2021;76:302-12.

10 Jacob ST, Banura P, Baeten JM, et al. The impact of early monitored management on survival in hospitalized adult Ugandan patients with severe sepsis: a prospective intervention study*. Crit Care Med 2012;40:2050-8.

11 Molyneux E, Ahmad S, Robertson A. Improved triage and emergency care for children reduces inpatient mortality in a resource-constrained setting. Bull World Health Organ 2006;84:3149.

12 Roy N, Kizhakke Veetil D, Khajanchi MU, et al. Learning from 2523 trauma deaths in India- opportunities to prevent in-hospital deaths. BMC Health Serv Res 2017;17:1-8.

13 Hogan $\mathrm{H}$, Healey F, Neale G, et al. Preventable deaths due to problems in care in English acute hospitals: a retrospective case record review study. BMJ Qual Saf 2012;21:737-45.

14 McQuillan P, Pilkington S, Allan A, et al. Confidential inquiry into quality of care before admission to intensive care. BMJ 1998;316:1853-8.

15 Goulet H, Guerand V, Bloom B. Unexpected death within 72 hours of emergency department visit: were those deaths preventable? Critical Care 2015;19:1-7.

16 Floyd J, Wu L, Hay Burgess D, et al. Evaluating the impact of pulse oximetry on childhood pneumonia mortality in resource-poor settings. Nature 2015;528:S53.

17 King C, Banda M, Bar-Zeev N, et al. Care-seeking patterns amongst suspected paediatric pneumonia deaths in rural Malawi. Gates Open Res 2020:4:178.

18 Kayambankadzanja RK, Schell CO, Mbingwani I, et al. Unmet need of essential treatments for critical illness in Malawi. PLoS One 2021;16:e0256361. 
19 Baker T, Lugazia E, Eriksen J, et al. Emergency and critical care services in Tanzania: a survey of ten hospitals. BMC Health Serv Res 2013;13:140

20 Reynolds TA, Sawe H, Rubiano AM. Strengthening Health Systems to Provide Emergency Care. In: Disease control priorities: improving health and reducing poverty. 3 edn. Washington (DC): The International Bank for Reconstruction and Development / The World Bank, 2017.

21 Abdu M, Wilson A, Mhango C, et al. Resource availability for the management of maternal sepsis in Malawi, other low-income countries, and lower-middle-income countries. Int J Gynaecol Obstet 2018;140:175-83.

22 Baker T, Schell CO, Lugazia E, et al. Vital signs directed therapy: improving care in an intensive care unit in a low-income country. PLoS One 2015;10:e0144801.

23 Diaz JV, Riviello ED, Papali A, et al. Global critical care: moving forward in resource-limited settings. Ann Glob Health 2019;85:3.

24 Schell CO, Beane A, Kayambankadzanja RK, et al. Global critical care: add essentials to the roadmap. Ann Glob Health 2019;85:97.

25 Schell CO, Gerdin Wärnberg M, Hvarfner A, et al. The global need for essential emergency and critical care. Crit Care 2018;22:284.

26 Dalkey NC. An experimental study of group opinion: the Delph method. Futures 1969;1:408-26.

27 Ward A. Advanced medical life support assessment for the medical patient. Burlington: Jones and Bartlett, 2018.

28 Henry S. ATLS 10th edition offers new insights into managing trauma patients. Bull Am Coll Surg 2018.

29 World Health Organization. Clinical care for severe acute respiratory infection: toolkit: COVID-19 adaptation. Geneva: World Health Organization, 2020.

30 World Health Organization. COVID-19 clinical management: living guidance, 25 January 2021: World Health organization, 2021. Available: https://www.who.int/publications/i/item/WHO-2019-nCoVclinical-2021-1 [Accessed 21 Apr 2021].

31 Jhpiego. Helping Mothers Survive Essential Care for Labor \& Birth (African Graphics), 2019. Available: http://reprolineplus.org/ resources/helping-mothers-survive-essential-care-labor-birthafrican-graphics [Accessed 17 Mar 2021].

32 World Health Organization. Emergency triage assessment and treatment (ETAT) course. Switzerland: Genveva, 2005.

33 American Academy of Pediatrics. APLS: the pediatric emergency medicine resource. Available: https://www.aap.org/en-us/continuingmedical-education/life-support/APLS-The-Pediatric-EmergencyMedicine-Resource/Pages/APLS-The-Pediatric-EmergencyMedicine-Resource.aspx [Accessed 17 Mar 2021].

34 World Health Organization. Monitoring emergency obstetric care : a handbook, 2009. Available: https://apps.who.int/iris/handle/10665/ 44121 [Accessed 17 Mar 2021].

35 World Health Organization. Guidelines for essential trauma care. World Health Organization, 2004

36 World Health Organization. UHC compendium. health interventions for universal health coverage. Available: https://www.who.int/ universal-health-coverage/compendium [Accessed 17 Mar 2021].

37 World Health Organization. WHO model Lists of essential medicines, 2019. Available: https://www.who.int/groups/expert-committee-onselection-and-use-of-essential-medicines/essential-medicines-lists [Accessed 17 Mar 2021].

38 World Health Organization. WHO recommendations on newborn health: guidelines approved by the WHO Guidelines Review Committee. World Health Organization, 2017.

39 World Health Organization. Basic emergency care: approach to the acutely ill and injured. World Health Organization, 2018.

40 Vogel C, Zwolinsky S, Griffiths C, et al. A Delphi study to build consensus on the definition and use of big data in obesity research. Int J Obes 2019;43:2573-86.

41 Lozano LM, García-Cueto E, Muñiz J. Effect of the number of response categories on the reliability and validity of rating scales. Methodology 2008;4:73-9.

42 Akins RB, Tolson H, Cole BR. Stability of response characteristics of a Delphi panel: application of bootstrap data expansion. BMC Med Res Methodol 2005;5:1-12.
43 Marshall JC, Bosco L, Adhikari NK, et al. What is an intensive care unit? A report of the task force of the world Federation of societies of intensive and critical care medicine. J Crit Care 2017;37:270-6.

44 World Health Organization. Priority medical devices list for the COVID-19 response and associated technical specifications: interim guidance, 2020. Available: https://apps.who.int/iris/handle/10665/ 336745 [Accessed 17 Mar 2021].

45 Cecconi M, Hernandez G, Dunser M, et al. Fluid administration for acute circulatory dysfunction using basic monitoring: narrative review and expert panel recommendations from an ESICM Task force. Intensive Care Med 2019;45:21-32.

46 Smith GB, Prytherch DR, Meredith P, et al. The ability of the National early warning score (news) to discriminate patients at risk of early cardiac arrest, unanticipated intensive care unit admission, and death. Resuscitation 2013;84:465-70.

47 Winters BD, Weaver SJ, Pfoh ER, et al. Rapid-response systems as a patient safety strategy: a systematic review. Ann Intern Med 2013;158:417-25.

48 Baelani I, Jochberger S, Laimer T, et al. Availability of critical care resources to treat patients with severe sepsis or septic shock in Africa: a self-reported, continent-wide survey of anaesthesia providers. Crit Care 2011;15:R10.

49 Maaløe N, Ørtved AMR, Sørensen JB, et al. The injustice of unfit clinical practice guidelines in low-resource realities. Lancet Glob Health 2021;9:e875-e879.

50 Callaghan M, Ford N, Schneider H. A systematic review of taskshifting for HIV treatment and care in Africa. Hum Resour Health 2010;8:8.

51 Duke T, Wandi F, Jonathan M, et al. Improved oxygen systems for childhood pneumonia: a multihospital effectiveness study in Papua New Guinea. Lancet 2008;372:1328-33.

52 Luettel D, Beaumont K, Healey F. Recognising and responding appropriately to early signs of deterioration in hospitalised patients. London: The National Patient Safety Agency - NHS, 2007.

53 Dessap AM. Frugal innovation for critical care. Intensive Care Med 2019;45:252-4.

54 Alhazzani W, Møller MH, Arabi YM, et al. Surviving sepsis campaign: guidelines on the management of critically ill adults with coronavirus disease 2019 (COVID-19). Intensive Care Med 2020;46:854-87.

55 Cleary SM, Wilkinson T, Tamandjou Tchuem CR, Tchuem CT, et al. Cost-effectiveness of intensive care for hospitalized COVID-19 patients: experience from South Africa. BMC Health Serv Res 2021;21:82

56 Barasa E, Kairu A, Ng'ang'a W, Maritim M, et al. Examining unit costs for COVID-19 case management in Kenya. BMJ Glob Health 2021;6:e004159.

57 Chang DW, Shapiro MF. Association between intensive care unit utilization during hospitalization and costs, use of invasive procedures, and mortality. JAMA Intern Med 2016;176:1492-9.

58 Baker T, Schell CO, Petersen DB, et al. Essential care of critical illness must not be forgotten in the COVID-19 pandemic. Lancet 2020;395:1253-4.

59 PATH. Malawi biomedical equipment for COVID-19 case management, 2021. Available: https://path.azureedge.net/media/ documents/Malawi Biomedical Equipment Assessment Report PATH_2021.01.25_final.pdf [Accessed 17 Mar 2021].

60 Mantena S, Rogo K, Burke TF. Re-Examining the race to send ventilators to low-resource settings. Respir Care 2020;65:1378-81.

61 Stein F, Perry M, Banda G, et al. Oxygen provision to fight COVID-19 in sub-Saharan Africa. BMJ Glob Health 2020;5:e002786.

62 PATH. COVID-19 oxygen needs tracker, 2020. Available: https:// www.path.org/programs/market-dynamics/covid-19-oxygen-needstracker/ [Accessed 17 Mar 2021]

63 Usher AD. Medical oxygen crisis: a belated COVID-19 response. Lancet 2021;397:868-9.

64 Fore $\mathrm{HH}$, Ghebreyesus TA, Watkins $\mathrm{K}$, et al. Leveraging the COVID-19 response to end preventable child deaths from pneumonia. Lancet 2020;396:1709-11.

65 Kruk ME, Gage AD, Arsenault C, et al. High-Quality health systems in the sustainable development goals era: time for a revolution. Lancet Glob Health 2018;6:E1162-E62. 